\title{
A Study to Determine Fetal and Newborn Bonding among Postnatal Women Admitted to Selected Hospitals of Udupi District, Karnataka
}

\author{
Darihunlang Pariat ${ }^{1} \quad$ Arkierupaia Shadap ${ }^{2}$ \\ ${ }^{1}$ North Eastern Indira Gandhi Regional Institute of Health and \\ Medical Sciences (NEIGRIHMS), Shillong, Meghalaya, India \\ 2 Sikkim Manipal College of Nursing, Sikkim Manipal University, \\ Sikkim, India
}

\begin{abstract}
Address for correspondence Darihunlang Pariat, North Eastern Indira Gandhi Regional Institute of Health and Medical Sciences (NEIGRIHMS), Shillong, Meghalaya 793018, India (e-mail: dari18pariat@gmail.com).
\end{abstract}

J Health Allied Sci ${ }^{\mathrm{NU}}$ 2019;9:1-5

\begin{abstract}
The emotional attachment that develops between a child and the caregiver is the first nonverbal interactive relationship of one's life. The bonding, which develops at this stage, would determine how one would relate to people around, throughout one's life. The aim of this study was to assess the maternal-neonatal bonding among postnatal mothers and to identify factors affecting bonding among postnatal mothers. The investigators adopted a descriptive survey research design using a purposive sampling technique to collect data from 60 postnatal mothers. Pretesting and reliability of the tool was done and it was found to be reliable. Tools were developed and sent for validation to experts. The data were collected after taking prior administrative permission and consent from the participants. The study findings show that out of 60 postnatal mothers, majority (51.6\%) were in the age group of 25 to 30 years. Majority (55\%) were multigravida and all (100\%) were married. Majority $(85.0 \%)$ of the mothers had a planned pregnancy, $93.3 \%$ did not undergo any fertility treatment, and majority $(91.7 \%)$ of them had a regular antenatal checkup. Of the 60 mothers, $81.6 \%$ had a high maternal-neonatal bonding and $18.3 \%$ had moderate bonding; none had low bonding. Further, the factors affecting maternal-neonatal bonding were analyzed with the cumulative bonding score. Out of the three factors, only social and

Keywords

- fetal

- newborn

- maternal

- postnatal women

- bonding emotional factors were included for simple linear regression analysis. Physical factors were excluded as there was no association with that of the cumulative bonding score $(r=00.16, p=0.372)$. Social and emotional factors affect the maternal-neonatal bonding; with every unit change in emotional factor, there will be 0.447 unit change in the bonding score. Similarly, for every unit change in the social factor, there will be 0.453 unit change in the bonding score.
\end{abstract}

\section{Introduction}

The emotional attachment that develops between a child and the caregiver is the first nonverbal interactive relationship of one's life. This bonding, which develops at this stage, would determine how one would relate to people around, throughout one's life. Children who are maltreated, or had a confusing and broken emotional relationship during their infancy, experience much difficulty in understanding their

DOI https://doi.org/ $10.1055 / \mathrm{s}-0039-1689073$ own emotions, or even other's feelings, which later in life hampers their ability to develop a trusting relationship and they experience many broken relationships. ${ }^{1}$

A secure attachment gives way to a positive outcome in the child's growth and development through positive confidence, self-esteem, and balanced emotions. Children who are deprived of this develop a disorganized attachment style. A safe attachment builds up a secure and holistic base for life; it creates awareness of a healthy holistic being, where
License terms

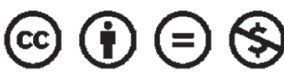


one is able to trust and be considerate to others, whereas a weak and an insecure bond fails to meet the infant's need for safety and security, and fails to understand the infant's cues and cries. An insecure bond, creates chaos in the fragile maternal-fetal relationship, leading to confusions to one's identity, feelings of loneliness and nonacceptance. ${ }^{2}$

A longitudinal descriptive study was conducted among 174 lower socioeconomic statuses of African-American women with their neonates, using a convenience sampling. The study aimed to assess the maternal-fetal attachment, prenatal health practices, and their relationship with the neonatal outcome. The instruments used for the study were the Maternal-Fetal Attachment Scale by Cranley, 1981, and the Health Practices in Pregnancy Questionnaire-II. Neonatal outcomes included were the neonate's gestational age and birth weight. $^{3}$

An article by Spinner points out different behaviors in a child's life which can vary at different times depending upon the "state" of the infant and the mother's "state" of mind which could directly or indirectly affect the bonding pattern. Miriam strongly alerts new mothers to know which stimulus to apply when an infant behaves in a particular manner at a particular development stage. ${ }^{4}$

In a study 315 Portuguese mothers in their early postnatal periods were assessed for emotional involvement of both mother and their infant, and the factors which contribute to both negative and positive and unclear emotions toward the infant. This was measured using the Portuguese version of the bonding scale and the Edinburgh Postnatal Depression Scale (EPDS). The results showed that when a mother is unemployed, single, and had lower education level, it affected her relationship with her infant because it elicited more negative emotions toward her infant which resulted in lower bonding score $(p<0.05)$. Negative emotions in EPDS showed $p<0.001$. Not clear emotions showed $p<0.05$. Thus, the results showed that maternal mood plays an important role in maternal-infant bonding. ${ }^{5}$

\section{Materials and Methods}

The study was conducted from the outpatient departments and postnatal wards of Kasturba Medical College Hospital, Manipal and Dr. TMA Pai Hospital of Udupi district, Karnataka, India. The investigators adopted a purposive sampling technique to collect data from 60 postnatal mothers who had given birth to healthy newborns either by cesarean or normal vaginal delivery. Pretesting and reliability of the tool was done and it was found to be reliable. The data were collected after taking prior administrative permission and consent from the participants. Tools were developed and sent for validation to experts. After the corrections and suggestions from experts the following tools were used for collecting data from the participants.

\section{Baseline variable}

Age, religion, education, income, type of family, parity index, marital status, occupation, number of years since last child birth, planned pregnancy, under gone any infertility treatment, type of delivery if normal vaginal birth, whether spontaneous or induced, and if cesarean whether it was emergency or elective, regular antenatal visits, and postnatal day, neonatal weight, and booked case.

\section{Tool 1: Maternal Postnatal Attachment Scale}

The tool consists of 19 items, divided into three categories: quality of attachment, absence of hostility, and pleasure in interaction. The items consist of three, four, or five options which need to be answered by the mother to complete the sentence, and few items are statements which could be answered on a 2-, 4-, or 5-point scale.

\section{Description of maternal neonatal bonding}

Maternal-neonatal bonding was measured using validated tools consisting of 19 items. A standardized Maternal Postnatal Attachment Scale (MPAS). Each item was given a minimum score of 1 and a maximum score of 5, 19 being the minimal score and 95 the maximum score. Further, the scores were arbitrarily divided as 44-60 (low maternal fetal bonding), 61-77 (moderate bonding), and 78-95 (high bonding).

\section{Tool 2: Factors affecting bonding scale}

This self-developed validated tool consists of 25 items. Items are scored on a 5-point Likert scale. The items were arbitrarily classified as strongly agree (5), agree (4), neutral (3), disagree (2), and strongly disagree (1). The items are subdivided into physical factors consisting of 8 items, emotional factors consisting of 9 items, and social factors consisting of 8 items. The minimum and maximum scores for the positive items were 25 and 125 . Negative items had reversed scoring. The factors affecting bonding scale were arbitrarily classified as low attachment (1-42), moderate attachment (43-84), and high attachment (85-125).

\section{Findings}

The data presented in - Table 1 shows that out of 60 postnatal mothers, majority (51.6\%) were of the age group 25 to 30 years. Majority (80\%) were Hindus, (38.3\%) had qualification of middle school certificate, majority (26.0\%) of the mothers had a monthly family income of Rs. 8,010 to 12,019. Majority (68.3\%), of the mothers lived in joint families and (55\%) were multigravida. All mothers (100\%) in the study were married and majority $(86.7 \%)$ of them were unemployed. Majority $(85.0 \%)$ of the mothers had a planned pregnancy with $93.3 \%$ of the mothers did not undergo any fertility treatment and majority (91.7\%) of them had a regular antenatal checkup.

Findings in - Fig. 1, show that out of 60 postnatal mothers, $81.6 \%$ had a high maternal-neonatal bonding, $18.3 \%$ had moderate bonding, and none had low bonding.

Data in -Table 2 describe the mean and standard deviation of physical, emotional, and social factors among postnatal mothers.

Further, to identify the factors affecting maternal neonatal bonding, a linear regression model ( $\mathbf{- T a b l e ~} \mathbf{3}$ ) was used to find the relationship between the bonding score and the factors, namely, the physical, emotional, and the social 
Table 1 Frequency and percentage distribution of sample characteristics of postnatal mothers

\begin{tabular}{|c|c|c|}
\hline \multicolumn{3}{|l|}{$N=60$} \\
\hline Variables & Frequency (f) & Percentage (\%) \\
\hline \multicolumn{3}{|l|}{ 1. Age } \\
\hline $19-24$ & 14 & 23.3 \\
\hline $25-30$ & 31 & 51.6 \\
\hline $31-37$ & 15 & 25 \\
\hline \multicolumn{3}{|l|}{ 2. Religion } \\
\hline Hindu & 48 & 80.0 \\
\hline Christian & 6 & 10.0 \\
\hline Muslim & 6 & 10.0 \\
\hline \multicolumn{3}{|l|}{ 3. Education } \\
\hline Illiterate & 7 & 11.7 \\
\hline Primary school certificate & 2 & 3.3 \\
\hline Middle school certificate & 23 & 38.3 \\
\hline High school certificate & 20 & 33.3 \\
\hline Intermediate/post high school diploma & 2 & 3.3 \\
\hline Graduate/post graduate & 5 & 8.3 \\
\hline Profession/ honors. & 1 & 1.7 \\
\hline \multicolumn{3}{|l|}{ 4. Monthly family income (in rupees) } \\
\hline$>3,2050$ & 2 & 3.3 \\
\hline $16,020-32,049$ & 7 & 11.7 \\
\hline $12,020-16,019$ & 12 & 20.0 \\
\hline $8,010-12,019$ & 16 & 26.7 \\
\hline $4,810-8,009$ & 11 & 18.3 \\
\hline $1,601-4,809$ & 7 & 11.7 \\
\hline$>1,600$ & 5 & 8.3 \\
\hline \multicolumn{3}{|l|}{ 5. Type of family } \\
\hline Joint family & 41 & 68.3 \\
\hline Nuclear family & 16 & 26.7 \\
\hline Extended family & 3 & 5.0 \\
\hline \multicolumn{3}{|l|}{ 6. Parity index } \\
\hline Primigravida & 27 & 45.0 \\
\hline Multigravida & 33 & 55.0 \\
\hline \multicolumn{3}{|l|}{ 7. Occupation } \\
\hline Employed & 8 & 13.3 \\
\hline House wife & 52 & 86.7 \\
\hline \multicolumn{3}{|l|}{ 8. Planned pregnancy } \\
\hline Yes & 51 & 85.0 \\
\hline No & 9 & 15.0 \\
\hline \multicolumn{3}{|l|}{ 9. Fertility treatment } \\
\hline Yes & 4 & 6.7 \\
\hline No & 56 & 93.3 \\
\hline \multicolumn{3}{|l|}{ 10. Regular antenatal checkup } \\
\hline Yes & 55 & 91.7 \\
\hline No & 5 & 8.3 \\
\hline \multicolumn{3}{|l|}{ 11. Type of delivery } \\
\hline NVD & 40 & 66.7 \\
\hline CS & 20 & 33.3 \\
\hline
\end{tabular}

Abbreviations: NVD, normal vaginal delivery; CS, cesarian section. 


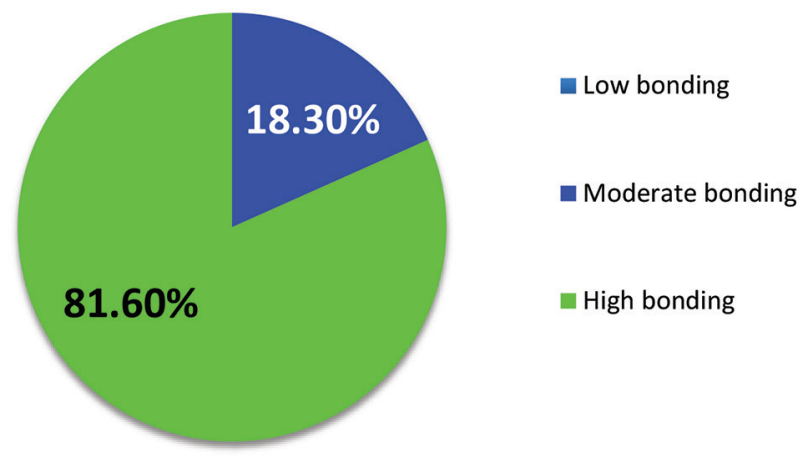

Fig. 1 Pie diagram of Maternal-Neonatal Bonding Score.

Table 2 Mean and standard deviation description of physical, emotional, and social factors among postnatal mothers

\begin{tabular}{|l|l|l|l|}
\hline Items & Range of score & Mean & SD \\
\hline Physical factors & $8-40$ & 27.38 & 6.770 \\
\hline Emotional factors & $9-45$ & 35.68 & 3.471 \\
\hline Social factors & $8-40$ & 29.77 & 4.014 \\
\hline
\end{tabular}

Table 3 Linear regression model on relationship between bonding score and physical, social, and emotional factors

\begin{tabular}{|l|l|l|l|l|l|}
\hline \multirow{2}{*}{ Model } & \multicolumn{2}{|l|}{$\begin{array}{l}\text { Unstandardized } \\
\text { coefficients }\end{array}$} & Standardized coefficients & \multirow{2}{*}{-Value } & \\
\cline { 2 - 5 } & B & Standard Error & Beta & 1.979 & 0.053 \\
\hline Social factor & 0.418 & 0.211 & 0.274 & 0.900 & 0.372 \\
\hline Physical factor & 0.096 & 0.107 & 0.106 & 1.898 & 0.063 \\
\hline Emotional factor & 0.459 & 0.242 & 0.259 & 1.00 \\
\hline
\end{tabular}

Note: Bonding score $=53.778+0.447^{*}$ Social factor score.

Bonding score $=53.778+0.453 *$ Emotional factor.

factors affecting bonding. The factors were analyzed with the cumulative bonding score. Out of the three factors, only social and emotional factors were included for simple linear regression analysis. Physical factor was excluded as there was no association with that of the cumulative bonding score $(r=00.16, p=0.372)$.

It may be interpreted in the study that the social and emotional factors affect the maternal neonatal bonding; with every unit change in emotional factor, there will be 0.447 unit change in the bonding score. Similarly, for every unit change in the social factor, there will be 0.453 unit change in the bonding score.

\section{Discussion}

A randomized controlled study, among 449 mothers, aimed to assess the intervention designed developed to improve the bonding pattern and security of infant attachment in South African women. The interventional group had good bonding (74\%) compared with the control group who had $63 \%$ bonding. ${ }^{6}$ The present study identified that two major factors that affect bonding are the emotional factor (anxiety, anger, depression, mood swings, fear, happiness, excitement) and the social factor (family support, seeking health advices, education, media, peer discussions), whereas the physical factor (pain, physical appearance of the baby, sex of the baby) had no significant relationship with maternal-neonatal bonding $(p \leq 0.05)$. A randomized control trial on 50 postcesarean mothers to assess effectiveness of a protocol in improving the duration of time spent by the baby with the mother after cesarean birth was conducted, where infants of the intervention group were given a chance for early physical contact, feeding, and longer duration with their mothers that resulted in improved maternal-infant bonding. A higher salivary cortisol level $(p<0.0001)$, increased infant weight $(p<0.05)$, and higher temperature were seen in the intervention group than that in the control group $(p<0.05) .^{7}$

In a longitudinal study 99 women at Japan were assessed in their late third trimester and during the immediate up to one month of postnatal period for postnatal depression, bonding failure, and attitudes toward pregnancy. The study findings were that anxiety during pregnancy predicts a bonding failure during postnatal period. Postnatal depression was mediated by having had a negative attitude toward their pregnancy (17 women reported that they did not feel real and 9 women felt perplexed) where bonding failure was imminent $(p<0.05){ }^{8}$ 


\section{Conclusion}

The participants in the study had a high bonding with their neonates. It has been observed that there is an association between maternal-neonatal bonding with the social and emotional factors. The study was valuable in assessing and identifying the factors which affect bonding and by identifying these factors, bonding pattern could be improved and many children and parents who are deprived of a strong bond could be assisted in forming the missing bond between them because an insecure bond could always be repaired. So, as health care professionals we play a major role in helping the antenatal and postnatal mothers to identify factors which help them enhance their bonding with their little ones.

\section{Conflict of Interest}

None declared.

\section{Acknowledgment}

The investigator(s) would like to thank the participants for their cooperation and participation during the study period.

\section{References}

1 Harvard Health Publications. Understanding the different ways of bonding and communicating with your child. Available at: http://www.helpguide.org/mental/bonding_attachment_ bond.htm. Accessed on May 20, 2019

2 Institution of Sustainable Development, Lucknow. Encyclopedia of Child and Family Welfare. Child Development-An Introduction. New Delhi, India: Anmol Publications Pvt. Ltd

3 Spinner MR. Maternal-infant bonding. Can Fam Physician 1978;24:1151-1153

4 Sedgmen B, McMahon C, Cairns D, Benzie RJ, Woodfield RL. The impact of two-dimensional versus three-dimensional ultrasound exposure on maternal-fetal attachment and maternal health behavior in pregnancy. Ultrasound Obstet Gynecol 2006;27(3):245-251

5 Fuller JR. Early patterns of maternal attachment. Health Care Women Int 1990;11(4):433-446

6 Cooper JP, Mark T, Leslie S. Improving quality of mother-infant relationship and infant attachment in socioeconomically deprived community in South Africa: randomized control trial. BMJ 2009;338:b974

7 Doan McK H, Zimerman A. Prenatal attachment: A developmental model. Perinat Psychol Med 2008;20

8 Figueiredo B, Costa R, Pacheco A, Pais A. Mother-to-infant emotional involvement at birth. Matern Child Health J 2009;13(4):539-549 